\title{
DEVELOPMENT AND CHARACTERIZATION OF A DAMAGE TOLERANT MICROSTRUCTURE FOR A NICKEL BASE TURBINE DISC ALLOY
}

\author{
R.M. Kearsey *, A.K. Koul *, J.C. Beddoes **, and C. Cooper *** \\ * Structures, Materials, and Propulsion Laboratory, Institute for Aerospace Research, National Research Council of Canada, \\ Ottawa, ON, Canada, K1A 0R6 \\ ** Department of Mechanical and Aerospace Engineering, Carleton University, Ottawa, ON, Canada, K1S 5B6 \\ *** Chief of Materials, Pratt \& Whitney Canada, Longueuil, Quebec, Canada, J4G 1A1
}

\begin{abstract}
$\underline{\text { Abstract }}$
A modified heat treatment has been developed for the nickel-base superalloy, PWA 1113, to create a damage tolerant microstructure (DTM) using mechanistic microstructural design concepts. The DTM was designed with the aim of imparting improved fatigue crack growth resistance without forfeiture of other vital properties such as tensile strength, stress rupture life, and low cycle fatigue lifetimes. This was achieved by optimizing the material's grain size, grain boundary morphology, and the intragranular precipitate size and distribution. Mechanical testing demonstrated that when compared to the conventional microstructure (CM), the short crack growth rate for the DTM was slower by a factor of 3 at room temperature, and 2.2 times slower at $482{ }^{\circ} \mathrm{C}$. Creep test results showed that at $690 \mathrm{MPa}(100 \mathrm{ksi})$ and $705^{\circ} \mathrm{C}$, the creep-rupture life was extended by a factor of almost 4 for the new DTM. Tensile test results indicated minimal strength losses for the DTM with respective YS and UTS values of $80 \%$ and $90 \%$ of the CM baseline values at both test temperatures.
\end{abstract}

\begin{abstract}
Introduction
Emerging safety standards for rotating engine components are now starting to demand properties in engineering materials, that may not meet the required specifications ${ }^{1,2}$. In particular, the damage tolerance specifications imposed upon turbine disc materials have prompted researchers to investigate ways to improve crack growth properties of presently used alloys without compromising the traditional safe life limits. As a result, a microstructural design philosophy has been successfully developed that is aimed at improving the damage tolerance of conventional disc materials. ${ }^{3}$

Damage tolerance, by definition, is the ability of the disc material to exhibit greater resistance to the growth of inherent or service induced flaws under creep and/or fatigue loading conditions, while still maintaining adequate low cycle fatigue properties, tensile strength, as well as stress rupture strength. ${ }^{4}$ Consequently, improving the damage tolerance of conventional Ni-base disc alloys has become an area of substantial interest amongst disc material manufacturers and engine designers alike.
\end{abstract}




\section{Design Lifing Methodologies}

All rotating turbine components, such as discs and spacers, have been designed on the basis of the safe-life design philosophy since the late sixties. This safe-life design approach states that a component must be designed for a finite service life during which no significant fatigue damage can occur. ${ }^{5}$ Specifically, disc life limits are set by the statistical number of low cycle fatigue (LCF) cycles required to form a detectable $800 \mu \mathrm{m}$ surface crack, in 1 out of 1000 components tested. ${ }^{6}$ This lifing methodology does not directly incorporate crack propagation behavior and therefore is unsuitable for damage tolerance applications.

Unlike traditional safe-life design methodologies, the damage tolerant design (DTD) philosophy includes the assumption that a flaw or a rogue defect is present during the initial design of the disc. ${ }^{7}$ The initial size of this flaw, $a_{i,}$ is assumed to be the minimum detectable crack size of the non-destructive inspection (NDI) technique used during engine maintenance. In contrast to the safe-life design methodology, that is dependant on pure statistical analysis of LCF tests, the DTD philosophy predicts disc lifetimes based on fatigue and/or creep crack growth using fracture mechanics principles. The fatigue crack growth rate (FCGR) of the material can be determined by performing a sufficient number of fatigue tests that reflect the in-service variables of stress amplitude, stress concentration, loading frequency and temperature. Once the FCGR of the material is known and a critical crack size, $a_{c}$, has been established, a safe inspection interval (SII) for the component can be determined. This SII is derived from the time it takes for $a_{i}$ to propagate to a predetermined dysfunction crack size, $a_{m}$, based on the FCGR of the disc material. After each SII, the disc is removed from service for inspection. If no cracks are found the disc is returned to service, otherwise, it is retired. Not only does this methodology prevent catastrophic failure by assuming the presence of inherent flaws from initial service, but it also prevents unnecessary discarding of discs that are retired prior to their actual full-life capability. A schematic of this life cycle management process is provided in Figure 1.

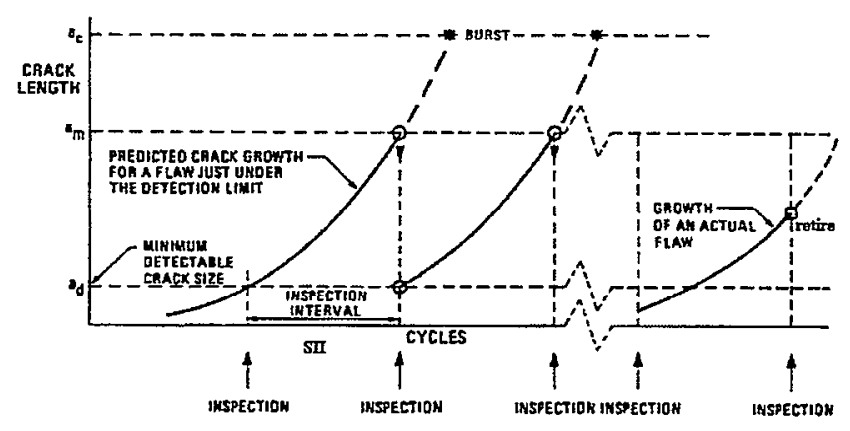

Figure 1: Safety Inspection Interval (SI) of DTD philosophy. ${ }^{8}$
It is apparent that the critical aspect of the DTD philosophy is the length of the SII. If the SII is too short, the maintenance downtime would make the process impractical. Therefore, materials that have consistently superior crack growth rate properties are essential for both the successful application of this life cycle management methodology and for meeting damage tolerance safety criteria. Hence, researchers must not restrict themselves solely to the area of damage tolerant microstructural design. They must also pay attention to the methods used to characterize the crack growth rate properties, which ultimately influence the SII predictions.

As the sensitivity of field NDI techniques improve, the study of short crack growth becomes important for the application of the DTD philosophy. This is largely due to the fact that, once nucleated, cracks in engineering components spend a large fraction of their lives as physically small cracks on the order of 5 to $1000 \mu \mathrm{m}$ in depth. ${ }^{9}$ In fact, the initiation and short crack growth periods generally account for a large portion of the total fatigue life of highly stressed components. Until recently, most fatigue research concentrated largely on the characterization of relatively long crack growth behavior of disc materials. Although this information is essential in itself, it only supplies the designer with a partial description of a material's overall fatigue behavior. Therefore, a damage tolerant microstructure (DTM) of a disc material must also retard short crack growth rates relative to its conventional microstructure (CM).

This paper describes the thermal processing route followed to create a DTM for PWA 1113, as well as the development of a crack monitoring technique that was developed for characterizing its short crack behavior. The influence of the new DTM on creep and tensile properties are also examined and compared with the mechanical properties of the CM at ambient as well as elevated temperatures.

\section{Experimental Materials and Methods}

\section{Material}

The conventional material used in this study was taken from an approximately 2-ft. diameter turbine disc that was provided by Pratt and Whitney Canada (P\&WC). The nominal composition (wt\%) for PWA 1113 is:

$\begin{array}{ccccccccc}\mathrm{Cr} & \mathrm{Co} & \mathrm{Mo} & \mathrm{Ti} & \mathrm{Al} & \mathrm{Zr} & \mathrm{B} & \mathrm{Fe} & \mathrm{Ni} \\ 16.5 & 14.0 & 4.08 & 4.50 & 2.02 & 0.07 & 0.007 & 0.06 & \text { Bal. }\end{array}$


The disc was produced by a forging method known as the Gatorizing process. This is a procedure that involves alloy powder consolidation through extrusion of a canned powder compact followed by isothermal forging. The CM contains a very fine microduplex $\gamma-\gamma^{\prime}$ grain size (ASTM 10) with a relatively straight grain boundary morphology and a, poorly distributed, coarse $\gamma^{\prime}$ precipitate structure, as seen in Figure 2.

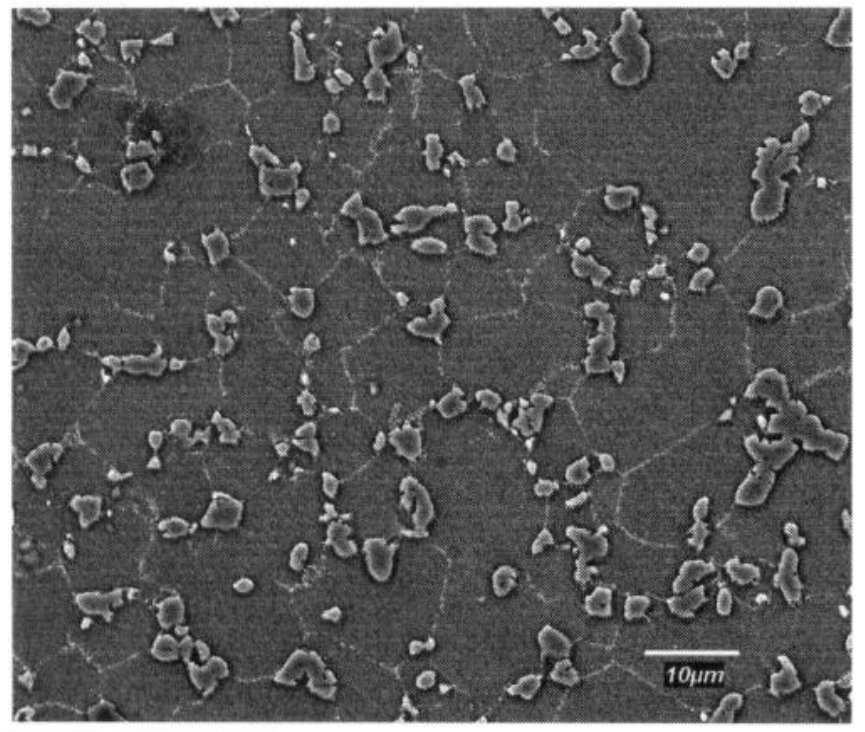

Figure 2: The CM of PWA 1113 showing large primary $\gamma^{\prime}$.

\section{DTM Development}

The DTM design philosophy was based on successful work by Koul et al. who developed DTM's for Inconel 718 and MERL 76 with marked improvements in fatigue and creep resistance ${ }^{3,7}$. Based on their past success, a similar methodology was adopted that involved:

1. Grain size optimization by determining the solution treatment conditions required to dissolve all second phase $\gamma^{\prime}$ precipitates while preventing excessive grain growth.

2. Determination of a post solutioning heat treatment sequence that defines the controlled-cooling rate range required to promote the formation of a serrated grain boundary structure through controlled $\gamma^{\prime}$ precipitation along the grain boundaries.

3. Determination of an appropriate aging sequence that produces the ideal amount, size, and distribution of $\gamma^{\prime}$ precipitates required to strengthen the $\gamma$ matrix.

\section{Fatigue Testing}

Short crack growth fatigue tests were performed using single edge notched (SEN) specimens in accordance with the ASTM-E647 specifications. Testing parameters included a loading frequency of $5 \mathrm{~Hz}$, a zero stress ratio with a maximum load of $32 \mathrm{kN}$, and a triangular waveform loading pattern. As seen in Figure 3, the SEN notch radius was $1.2 \mathrm{~mm}\left(0.049 \mathrm{in}\right.$.) to simulate the $\mathrm{K}_{\mathrm{T}}$ factor of 2.68 that is commonly found in the critical regions of the disc. Three specimens from each microstructural condition were tested at room temperature and $482^{\circ} \mathrm{C}$.

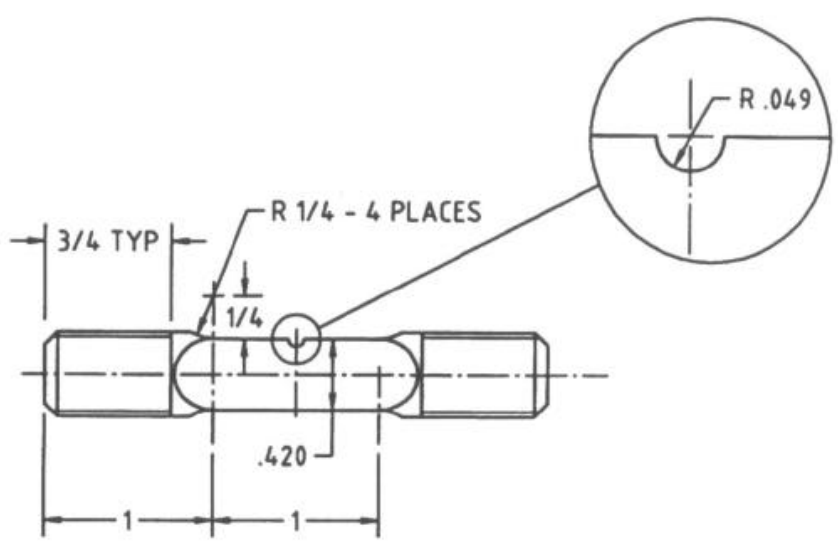

Figure 3: SEN specimen used for short crack fatigue testing.

Extensive experimental work was also performed to implement an alternating current potential difference (ACPD) technique required to continuously monitor the short crack growth rate properties without test interruption. Preparation involved meticulous placement of voltage probes and current leads to the specimen surface as seen in Figure 4 . Ten calibration tests were performed over a wide crack size range ( $40 \mu \mathrm{m}$ to $1500 \mu \mathrm{m})$ to determine the crack size-potential drop relationship. Figure 5 shows one such calibration test where a thumbnail crack of $748 \mu \mathrm{m}$ in length corresponded to a $52 \mathrm{mV}$ change in potential voltage. A 5-amp alternating current at a frequency of 130 $\mathrm{kHz}$ was used to give extremely high sensitivity of short crack detection to a depth of $1.5 \mathrm{~mm}$ below the specimen surface.

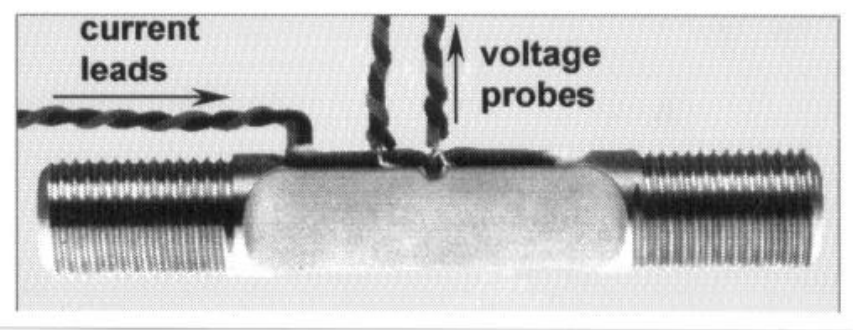

Figure 4: Specimen ACPD lead configuration.

\section{Tensile Testing}

Tensile tests were performed in accordance with ASTM-E8 at room temperature and $650{ }^{\circ} \mathrm{C}$. Strain data was gathered using a high temperature quartz-rod extensometer while monitoring simultaneous load readings from the MTS load cell. Multiple tests were conducted for the conventional and damage tolerant microstructures at each test temperature. 


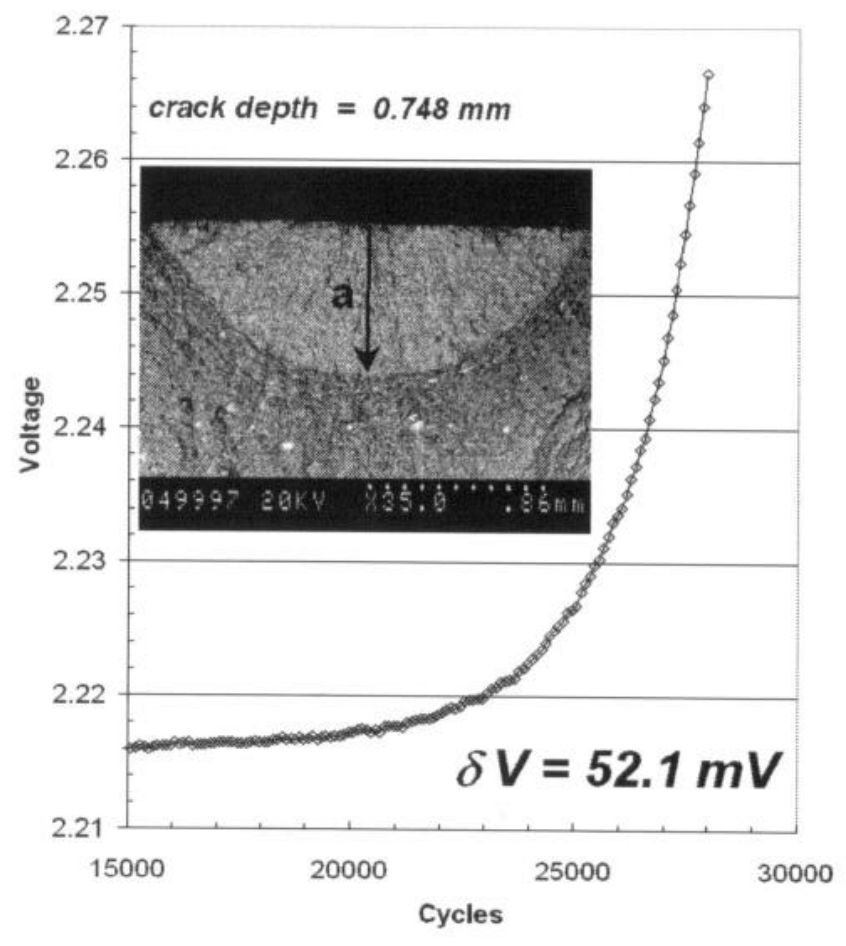

Figure 5: Sample crack calibration curve showing crack depth/potential drop relationship.

\section{Creep Testing}

Creep-rupture tests were performed in accordance with ASTM-E139 and were conducted at $705{ }^{\circ} \mathrm{C}$ under a constant load of $690 \mathrm{MPa}$ (100 ksi). Both microstructural conditions were tested for comparison.

\section{$\underline{\text { Results and Discussion }}$}

\section{Grain Size Optimization}

To determine the solutionizing temperature required to dissolve all $\gamma^{\prime}$ precipitates without the occurrence of excessive grain growth, a detailed grain coarsening study was performed. Figure 6 shows the grain coarsening behavior of the material over a wide range of solutioning temperatures and hold times. It is apparent from this figure that a major shift in grain size occurs over a very short temperature interval $\left(1130{ }^{\circ} \mathrm{C}\right.$ to $\left.1135{ }^{\circ} \mathrm{C}\right)$ for all solutioning hold times. It can therefore be deduced that, during this short interval, the $\gamma^{\prime}$ precipitates are fully dissolved, effectively removing all grain boundary pinning agents and permitting grain growth to occur. Hence, the temperature chosen for solutioning the $\gamma^{\prime}$ precipitate phase was at $1135^{\circ} \mathrm{C}$ just past the inflection point on the curve to prevent excessive grain growth. The chosen solutioning temperature resulted in a final DTM grain size of $\sim 70 \mu \mathrm{m}$ (ASTM 4).

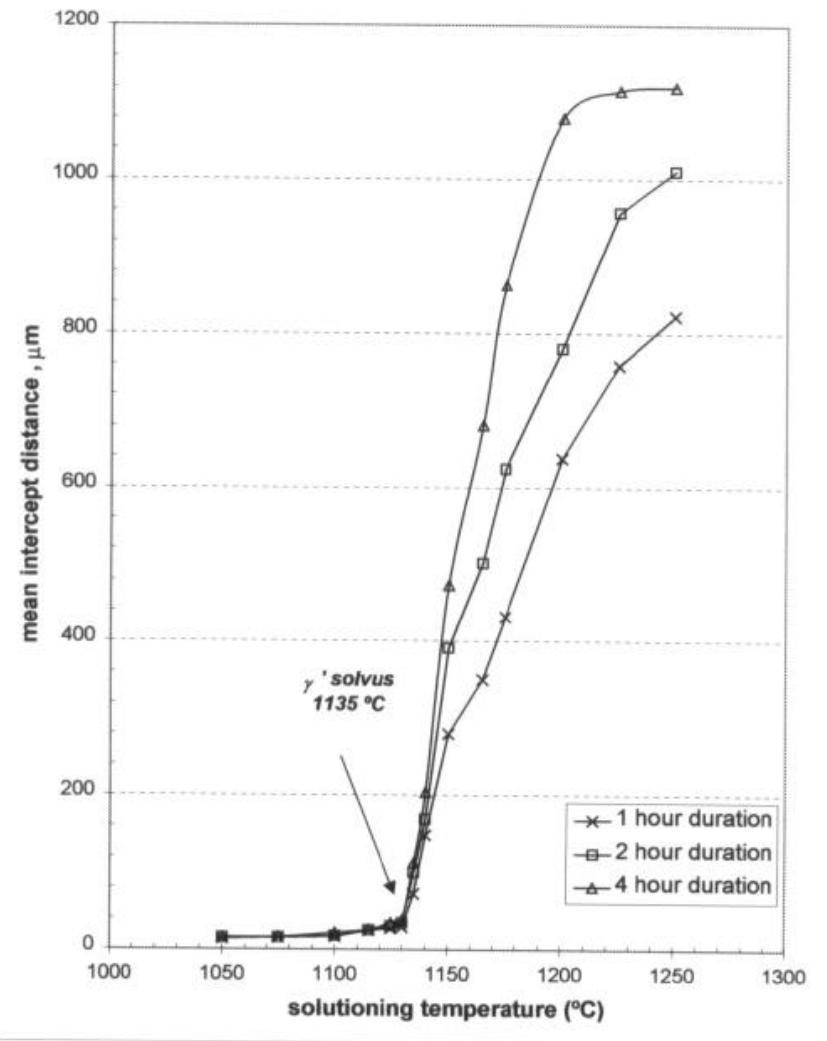

Figure 6: Grain coarsening behavior of PWA 1113.

\section{Grain Boundary Serrations}

Grain boundary serrations can be generated by controlled furnace cooling from the solution temperature. However, it has been determined by Koul et al. that only high volume fraction alloys with a sufficiently large lattice mismatch are capable of forming serrations during furnace cooling. ${ }^{10}$ Furthermore, the proposed strain energy differential model by Koul and Gessinger, states that there is a minimum particle size required for serration formation based on the following equation ${ }^{10}$,

$$
r_{c}=\frac{3 \gamma_{s t}}{4 \mu \delta^{2}}
$$

where $\gamma_{s t}$ is the interfacial energy due to the structural distortion caused by the misfit dislocations, $\delta$ is the particle-matrix misfit parameter, and $\mu$ is the shear modulus of the matrix. It should be noted that the model accounts for the varying effects of cooling rates on serration morphology if one considers the correlation between precipitate size and cooling time.

Once it has been established that the alloy is capable of forming grain boundary serrations the next logical step in DTM design is to determine the size of serrations required to optimize crack growth resistance. Wu and Koul have 
developed a constitutive model that predicts the optimum grain boundary serration size that effectively inhibits grain boundary sliding. ${ }^{11}{ }^{12}$ The model accurately describes the transient creep behavior of complex Ni-base superalloys with respect to the serration amplitude $(h)$ and the serration wavelength $(\lambda)$. The optimum serration geometry to prevent grain boundary sliding can be approximated by the simplified steady-state creep rate equation,

$$
\dot{\varepsilon}=\phi A_{0} \frac{D \mu b}{k T}\left(\frac{b}{d}\right)^{q}\left(\frac{l+r}{b}\right)^{q-1} \frac{\left(\sigma_{a}-\sigma_{i g}\right)\left(\sigma_{a}-\sigma_{i c}\right)}{\mu^{2}}
$$

where $A_{0}$ is a non-dimensional constant, $l$ is the grain boundary precipitate spacing, $r$ is the radius of the grain boundary particle, $d$ is the grain size, $q$ is the grain size index, $\mu$ is the elastic shear modulus, $\sigma_{a}$ is the applied tensile stress, $\sigma_{i g}$ is the tensile stress opposing dislocation glide, $\sigma_{i c}$ is the tensile stress opposing dislocation climb, and $\phi$ is the grain boundary serration factor defined by,

$$
\phi=\frac{2}{\sqrt{1+\left(\frac{\pi h}{\lambda}\right)^{2}}}-1
$$

There is an optimum range of serration amplitude and wavelength values required to reduce creep rate. From these equations, it is then possible to predict the $\gamma^{\prime}$ precipitate size required to form the appropriate serration $h$ and $\lambda$, necessary for suppressing grain boundary sliding phenomena. Equations (1) through (3) define the basic microstructural design criteria. No attempt was made however, to optimize the grain boundary carbide precipitate size and distribution in the present study.

Numerous heat treatment sequences were used to determine the appropriate cooling rate range required to heterogeneously nucleate $\gamma^{\prime}$ precipitates along the grain boundaries. Extremely fast cooling rates resulted in relatively small grain boundary precipitates $(<1 \mu \mathrm{m})$ that were ineffective in serration formation. In the other extreme, excessively slow cooling rates generated large precipitate growth that produced ineffective, oversized grain boundary serrations. The final cooling rate range was between $1^{\circ} \mathrm{C} / \mathrm{min}$ and $3^{\circ} \mathrm{C} / \mathrm{min}$ directly from the solvus temperature of $1135^{\circ} \mathrm{C}$ to a furnace removal temperature of $1060^{\circ} \mathrm{C}$. This sequence produced the optimum precipitate size $(\sim 1-3 \mu \mathrm{m})$ that generated grain boundary serrations throughout the microstructure's intergranular region, as seen in Figure 7. Similar to findings by Koul et al., the majority of grain boundary $\gamma^{\prime}$ precipitates responsible for grain boundary serrations are elliptical in shape and are always located within the concave side of the serration ${ }^{13}$.

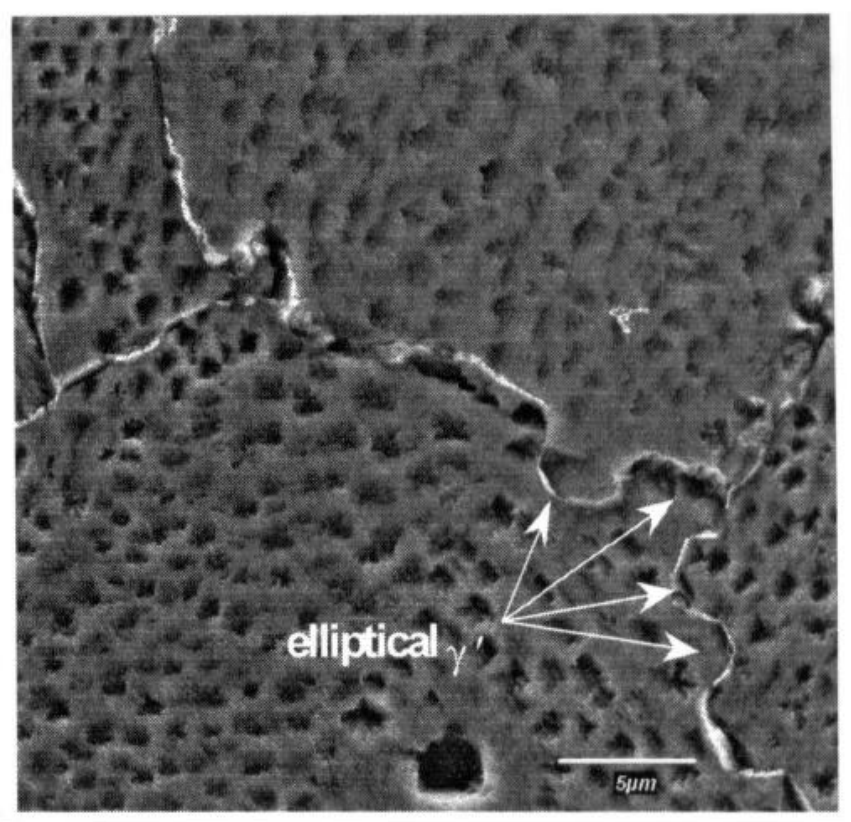

Figure 7: Grain boundary serrations in new DTM.

\section{Morphology and Distribution of $\gamma^{\prime}$}

The size, volume fraction, and distribution of the $\gamma^{\prime}$ precipitates are the three main variables that influence the degree of precipitation hardening in Ni-base superalloys. It is quite obvious from Figure 8, that the primary $\gamma^{\prime}$ size and distribution for the $\mathrm{CM}$ is quite large and poorly distributed throughout the matrix. Primary $\gamma^{\prime}$ for the $\mathrm{CM}$ condition are up to $10 \mu \mathrm{m}$ in diameter and are usually located along the grain boundaries, likely contributing little to the overall matrix strength. Precipitate optimization was accomplished by partially solutionizing the material at $1060^{\circ} \mathrm{C}$ for 1 hour which partially dissolved the intragranular $\gamma^{\prime}$ without any loss of grain boundary serration morphology. This was then followed by a single-step aging sequence that entailed heat treating at $760{ }^{\circ} \mathrm{C}$ for 16 hours which produced the ideal amount, size, and distribution of $\gamma^{\prime}$ precipitates required to strengthen the $\gamma$ matrix. Figure 9 shows the new precipitate morphology and distribution of the DTM. The new features include a smaller primary $\gamma^{\prime}$ precipitate size $(\sim 1 \mu \mathrm{m})$ that is more homogeneously distributed throughout the intragranular region, as well as a much finer secondary precipitate size. 


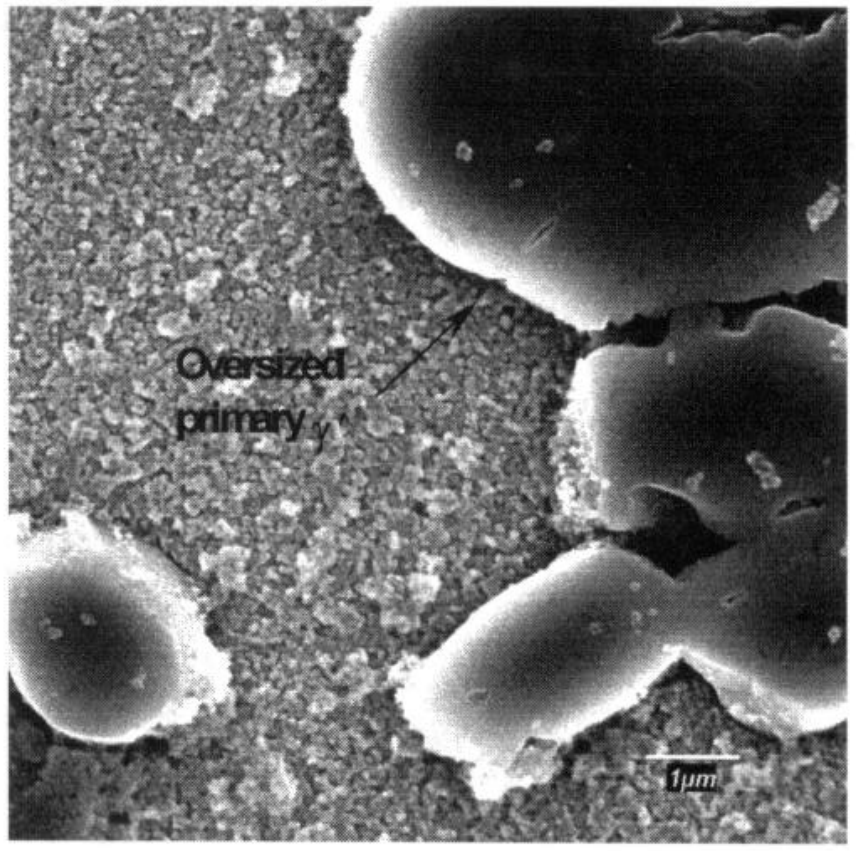

Figure 8: Morphology and distribution of $\gamma^{\prime}$ for CM condition.

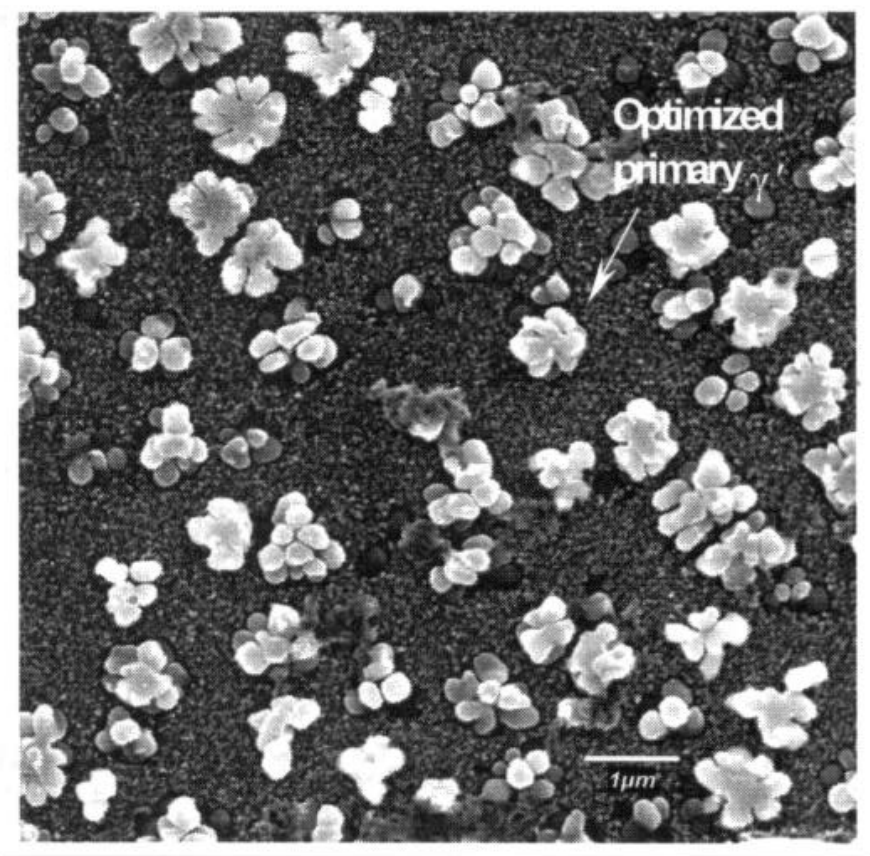

Figure 9: Morphology and distribution of $\gamma^{\prime}$ for DTM condition.

\section{Mechanical Properties}

Short Crack Fatigue Properties

Fatigue test results revealed that the DTM possessed better short crack fatigue resistance than the $\mathrm{CM}$ at both room temperature and at $482{ }^{\circ} \mathrm{C}$. For example, at a stress intensity $(\Delta \mathrm{K})$ of $10 \mathrm{MPa} \sqrt{\mathrm{m}}$, the crack growth rate for the DTM is 2.7 times slower at room temperature and 2.2 times slower at $482{ }^{\circ} \mathrm{C}$ compared to the $\mathrm{CM}$, as illustrated in Figures 10 and 11 respectively.

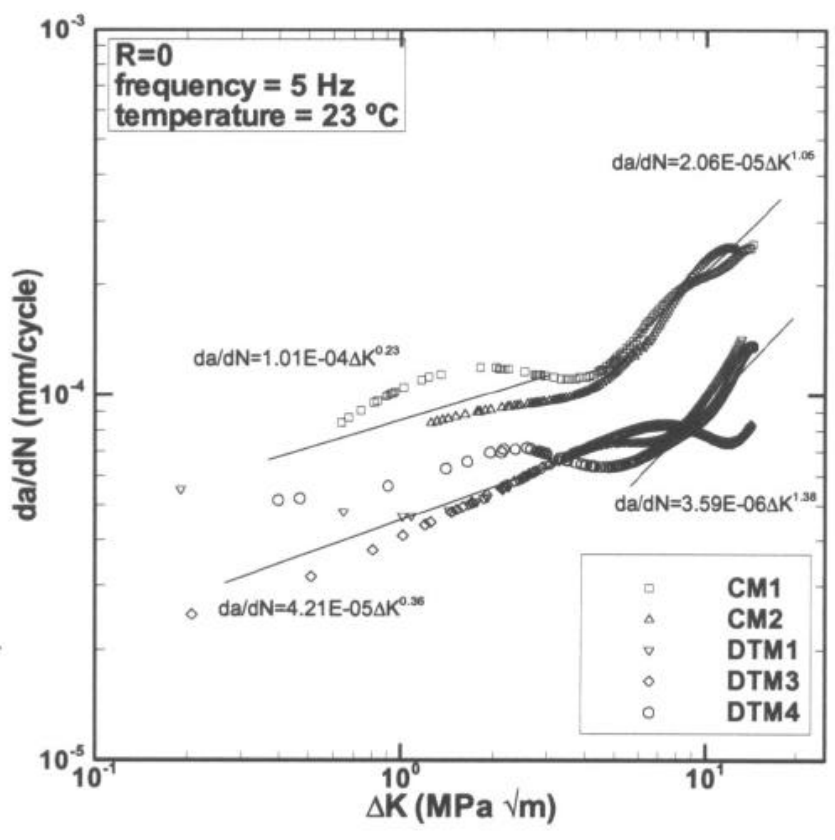

Figure 10: SCGR properties of CM and DTM at $23^{\circ} \mathrm{C}$.

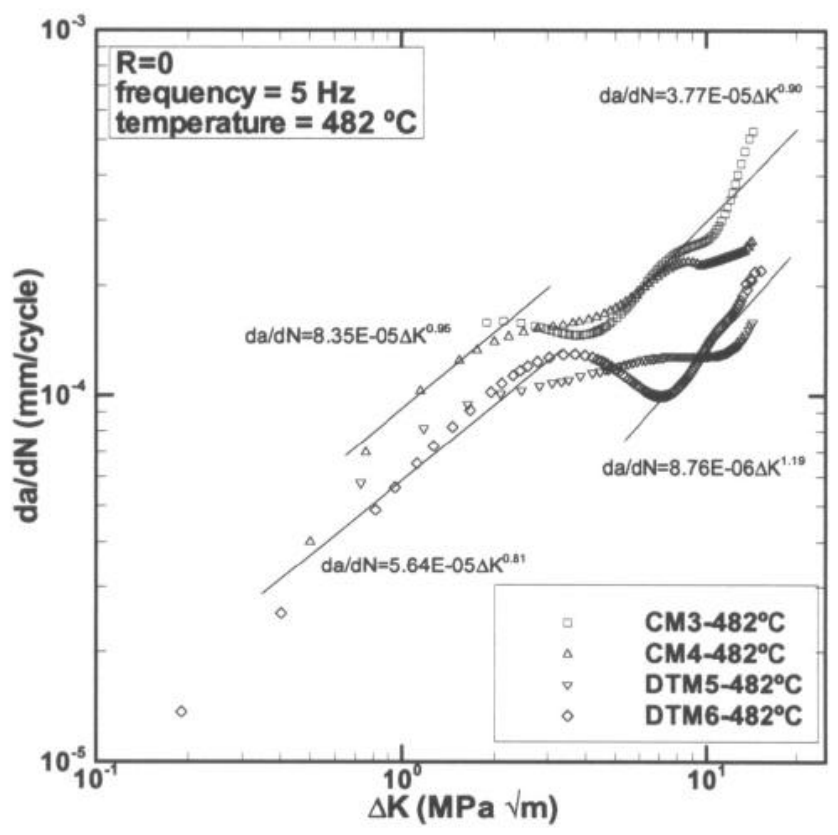

Figure 11: SCGR properties of CM and DTM at $482^{\circ} \mathrm{C}$.

It is apparent from both the room and elevated temperature fatigue curves presented, that short crack growth behavior does not conform to traditional long crack growth characteristics. Generally, there are two main defining properties of short cracks that distinguish them from typical long crack growth features.

1. Short cracks have generally been observed to exhibit faster and more irregular propagation rates compared to long crack data. ${ }^{14}$ 
2. Short crack propagation occurs at stress intensity factors $(\Delta \mathrm{K})$ well below the traditional threshold value $\left(\Delta \mathrm{K}_{\mathrm{th}}\right)$ for long crack growth. ${ }^{15}$

These two distinguishing properties of short cracks have been reported by numerous researchers, all of whom have reported similar anomalous short crack behavior. ${ }^{16}$ This is primarily due to the fact that microstructurally short crack growth, often deals with the propagation of cracks that do not abide by Linear Elastic Fracture Mechanics (LEFM) principles.

LEFM relies heavily on continuum mechanics principles for crack propagation. However, when dealing with short crack growth, the crack in the beginning is smaller than the actual grain size and microstructural features tend to influence crack propagation. This ultimately results in the breakdown of the material continuum and propagation exhibits a more discrete behavior. Due to the interference of short crack propagation by such features as grain boundaries and intragranular precipitates, the resulting growth rate is often irregular in nature ${ }^{17}$. When such an obstacle is encountered by the crack tip plastic zone, the growth rate tends to decrease followed by rapid acceleration upon traversing the barrier. This fluctuating crack growth behavior is visible in Figures 10 and 11, which show periods of deceleration and acceleration at relatively low $\Delta \mathrm{K}$ levels. These inflection points on the curves occur at $\Delta \mathrm{K}$ levels that are indicative of crack depths equivalent in length to the average microstructural grain size. This suggests that the initial deceleration is most likely due to dislocation pile-up at the impeding grain boundary, followed by rapid acceleration once sufficient stress intensity has been attained for slip band extension into the neighboring grain. As the crack length increases, microstructural features become less effective, crack tip deformation increases, and propagation behavior tends toward continuum mechanics principles (i.e long crack growth). ${ }^{18}$

The improvements in short crack growth rate properties can be explained on the basis of differences in the fracture modes observed in Figures 12 and 13. In Figure 12, it is obvious that the fracture mode of the $\mathrm{CM}$ is transgranular, with evidence of striations or faceted crack growth across the grains. There is also evidence of the ineffectiveness of the large overaged $\gamma^{\prime}$ precipitates in retarding crack growth. The DTM fracture surface also exhibits a transgranular fracture, however, due to the finer, more dispersed $\gamma^{\prime}$ precipitate morphology, crack growth is decreased within the intragranular region. This is most likely caused by the combination of crack deflection around the precipitates which prevents slip-band extension within the grain itself as well as the larger DTM grain size.

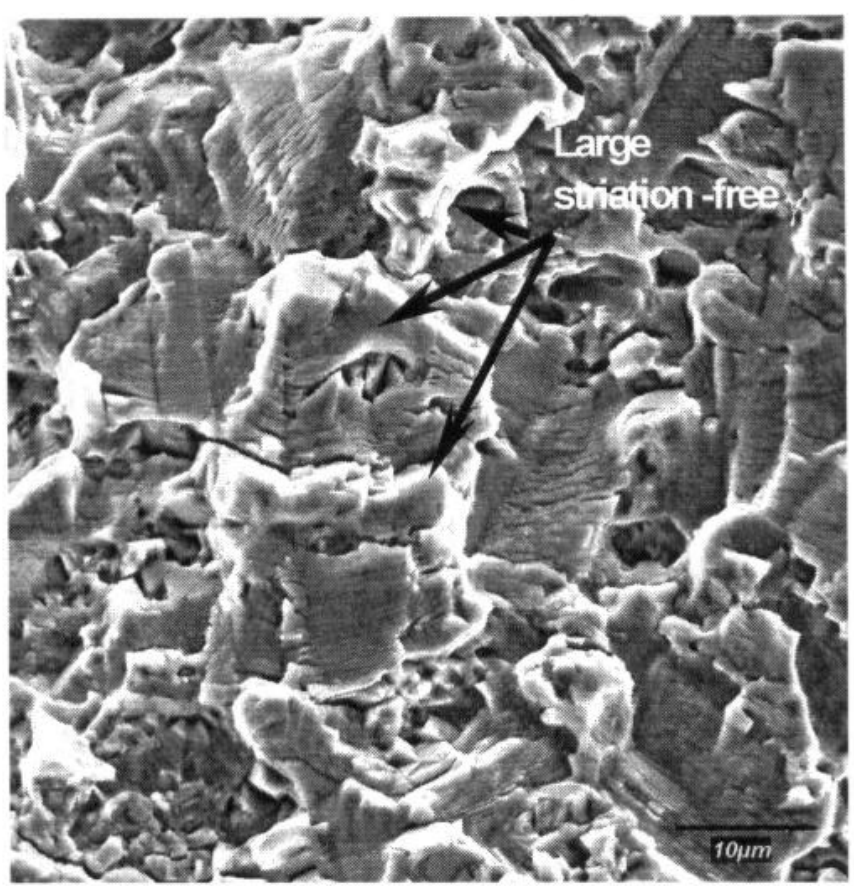

Figure 12: Fractograph of $\mathrm{CM}$ from $482^{\circ} \mathrm{C}$ fatigue test.

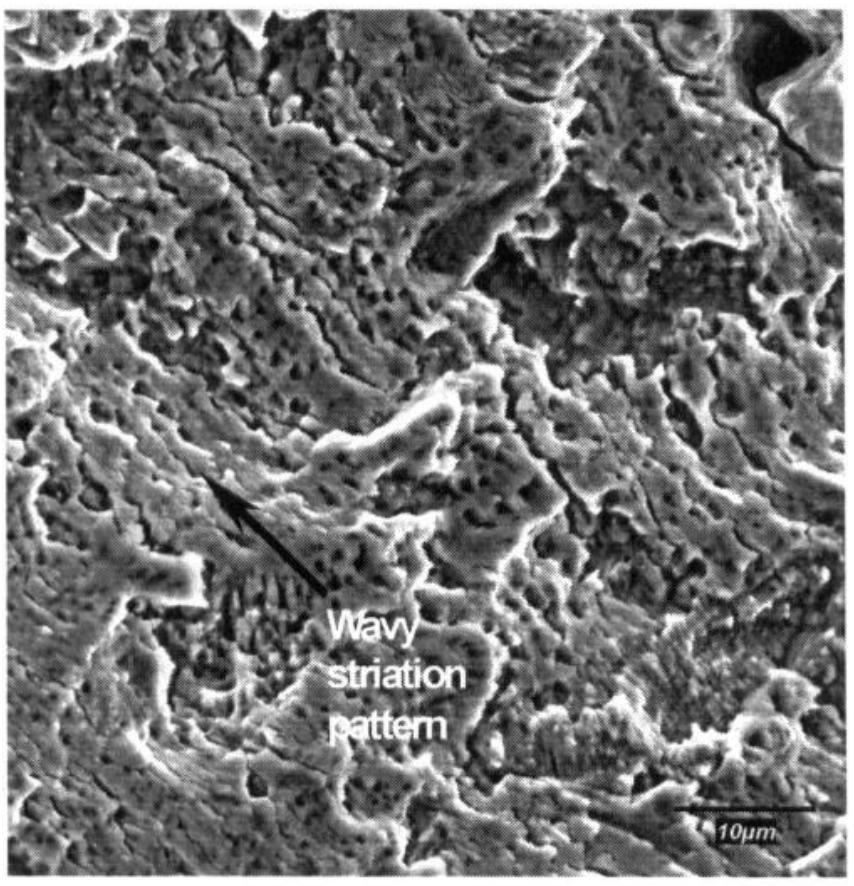

Figure 13: Fractograph of DTM from $482^{\circ} \mathrm{C}$ fatigue test.

\section{Creep Rupture Properties}

In addition to the improved short crack growth rate properties of the DTM, the creep-rupture tests results demonstrate a marked improvement over the creep properties of the $\mathrm{CM}$ material. It was predicted that the DTM would have better creep resistance due to it's larger grain size and serrated grain boundary morphology. In fact, the test results shown in Figure 14 indicate that at an initial 
stress level of $690 \mathrm{MPa}(100 \mathrm{ksi})$ and at a temperature of $705{ }^{\circ} \mathrm{C}$, the creep-rupture life was almost 3.4 times longer for the DTM.

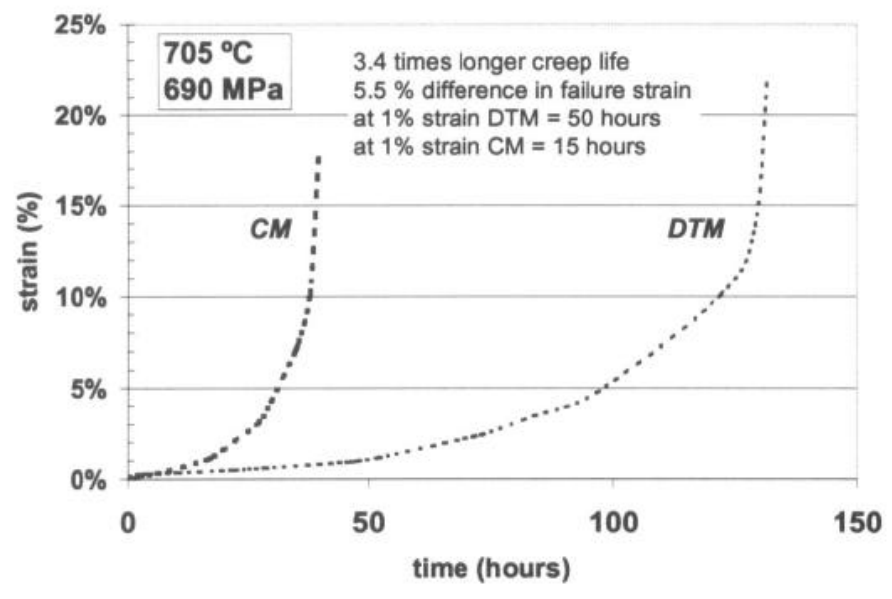

Figure 14: Creep-Rupture test results for CM and DTM.

Furthermore, it is apparent from the creep fractograph in Figure 15 that the fracture mode of the DTM is intergranular, as indicated by the irregular topography and grain boundary relief. Compared to the fracture surface of the CM, Figure 16, the DTM has a more highly featured surface profile. Although the fracture mode of the CM is also intergranular, it does not possess the same degree of rough topography due to its smaller grain size. This small grain size $(\sim 13 \mu \mathrm{m})$, results in a relatively smooth fracture surface almost indistinguishable from the transgranular overload section of the specimen as shown in Figure 16. The intergranular fracture in both materials suggests that the test temperature of $705{ }^{\circ} \mathrm{C}$ was indeed above the equicohesive limit. In other words, at this temperature the grain interiors retained superior creep resistance compared to the grain boundaries.

The data from Figure 14 also reflects two other important results,

1. There is a delayed onset of tertiary creep ( $\sim 50 \mathrm{hrs})$ for the DTM as compared to the CM ( $\sim 5 \mathrm{hrs})$

2. The tertiary creep time interval is much longer for the DTM.

As for the superior creep resistance of the DTM, it may be attributed to a combination of a coarser grain size, the serrated grain boundary morphology, and the smaller $\gamma^{\prime}$ precipitate size and more uniform $\gamma^{\prime}$ distribution. The larger grain size $(70-100 \mu \mathrm{m})$ of the DTM means that there is a lower grain boundary fraction present that could serve as creep fracture paths in the material. The serrated morphology of the DTM may also slow down surface creep crack propagation by presenting a more tortuous crack path, as compared to the relatively planar boundaries of the CM. These microstructural features are known to suppress grain boundary sliding. The finer $(1 \mu \mathrm{m})$ precipitate size, as well as their decoration along the grain boundaries, may also retard crack propagation. The higher fraction of grain boundary pinning, due to the more dispersed nature of these precipitates, results in higher intergranular strength. In contrast, the CM precipitate size is extremely large $(10 \mu \mathrm{m})$ and poorly distributed playing no role in grain boundary strengthening.

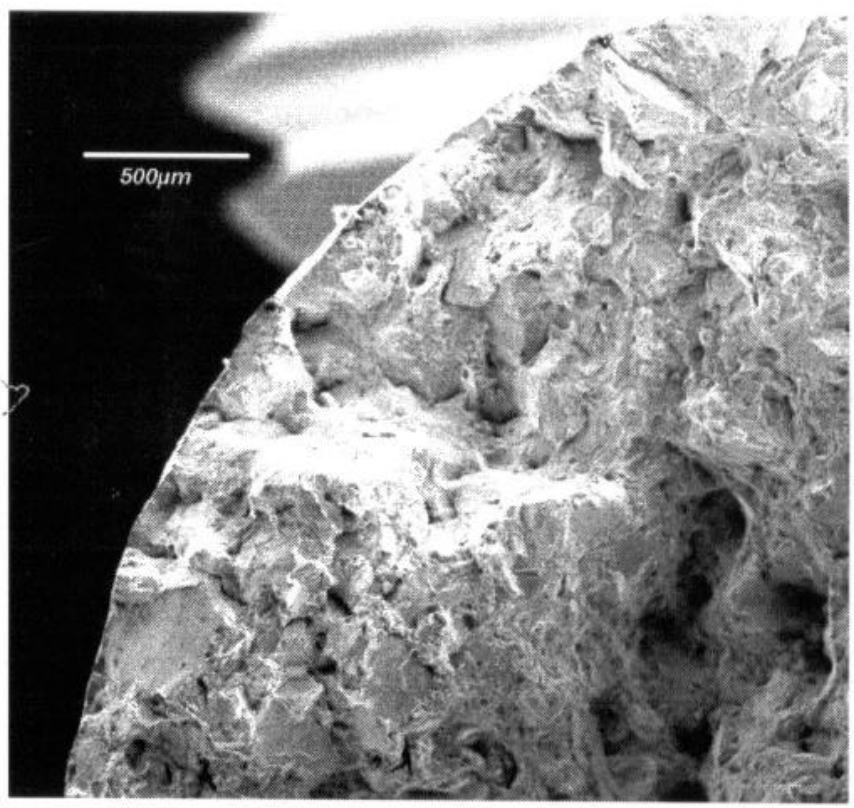

Figure 15: Creep surface of DTM after 131.5 hours at $705{ }^{\circ} \mathrm{C}$ and $690 \mathrm{MPa}$.

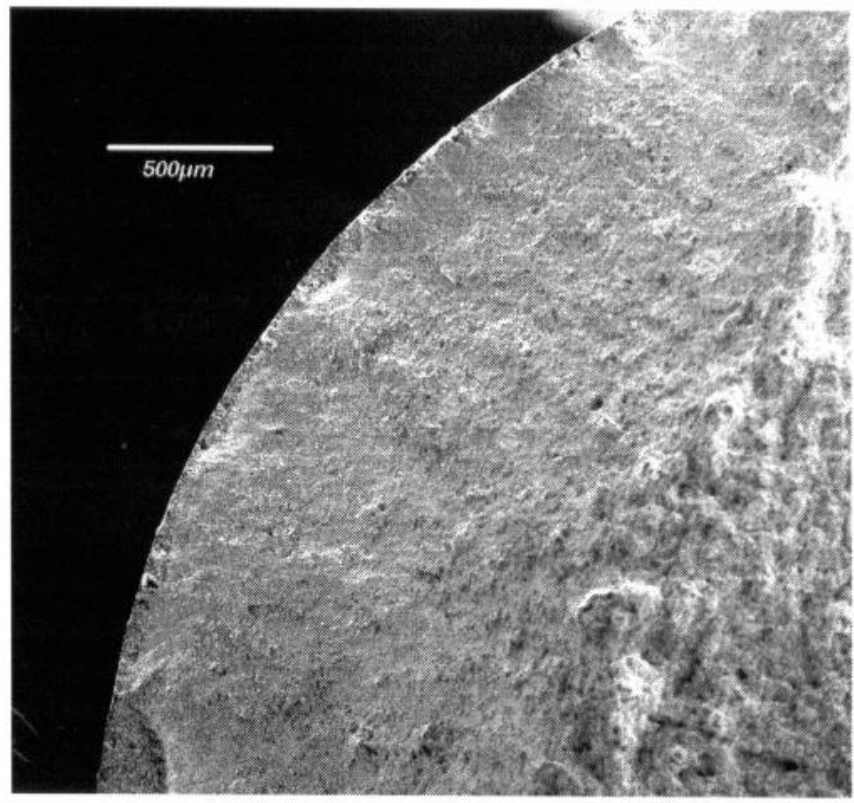

Figure 16: Creep surface of $\mathrm{CM}$ after 39.4 hours at $705{ }^{\circ} \mathrm{C}$ and 690-MPa. 


\section{Tensile Properties}

Tensile tests were conducted at room temperature and at $650{ }^{\circ} \mathrm{C}$. Figure 17 and Figure 18 show the tensile test results for room temperature and $650{ }^{\circ} \mathrm{C}$ respectively. Tensile test results indicated minimal strength losses for the DTM in terms of YS and UTS values with $80 \%$ and $90 \%$ of the CM baseline values for both room temperature and 650 ${ }^{\circ} \mathrm{C}$. From these results it can be seen that the UTS and YS values of the new damage tolerant microstructure are comparable to that of the conventional microstructure. Yield and ultimate strengths are slightly lower in the new DTM as was to be expected due to the larger grain size present.

Room temperature and high temperature tests also showed an increase in specimen elongation for the new DTM. Average elongation values for room temperature tests were $12 \%$ and $18 \%$ for the CM and DTM respectively. Likewise, at $6500^{\circ} \mathrm{C}$, the average elongation values were $12 \%$ for the $\mathrm{CM}$ and $15 \%$ for the DTM. This trend is consistent with the improvement in creep ductility of the DTM as shown in Figure 14. The increased ductility of the new DTM may also be accountable for the improved high temperature fatigue resistance observed. Bain et al. have developed an improved DTM for the Ni-base superalloy Udimet 720 by simply increasing the overall grain size. ${ }^{12}$ Their findings have shown that at the expense of marginal losses in tensile strength, the increased ductility of the coarser grain sized material produces significant improvements in high temperature fatigue resistance as well as stress rupture life.

\section{Conclusions}

A successfil DTM for the Ni-base superalloy, PWA 1113, has been designed. The DTM was produced by implementing a modified heat treatment sequence that optimized the grain size, grain boundary morphology, and $\gamma^{\prime}$ precipitate size and distribution. The new heat treatment sequence imparted a controlled serrated grain boundary morphology, coarser grain size, and a finer, more uniformly distributed $\gamma^{\prime}$ size. Short crack propagation rates were decreased by a factor of 3 at room temperature and a factor of 2.2 at $482{ }^{\circ} \mathrm{C}$. Grain size had a profound effect on the shape of $\Delta \mathrm{K}$ versus crack growth rate correlation. At $705^{\circ} \mathrm{C}$ and $690 \mathrm{MPa}$, the creep rupture life of the DTM was extended by a factor of almost 4. Marginal losses in proof strength and ultimate strength were also observed during room temperature and high temperature tensile tests. Improved damage tolerance properties can be directly related to the improved grain boundary strength of the DTM that was invoked by controlled-cooling heat treatments. The finer $\gamma^{\prime}$ precipitate size and distribution also contributed to slower intragranular crack propagation rates by impeding dislocation motion through the grain interiors. These findings for the new DTM are in good agreement to earlier damage tolerance studies for comparable Ni-base superalloys ${ }^{3,7,13}$.

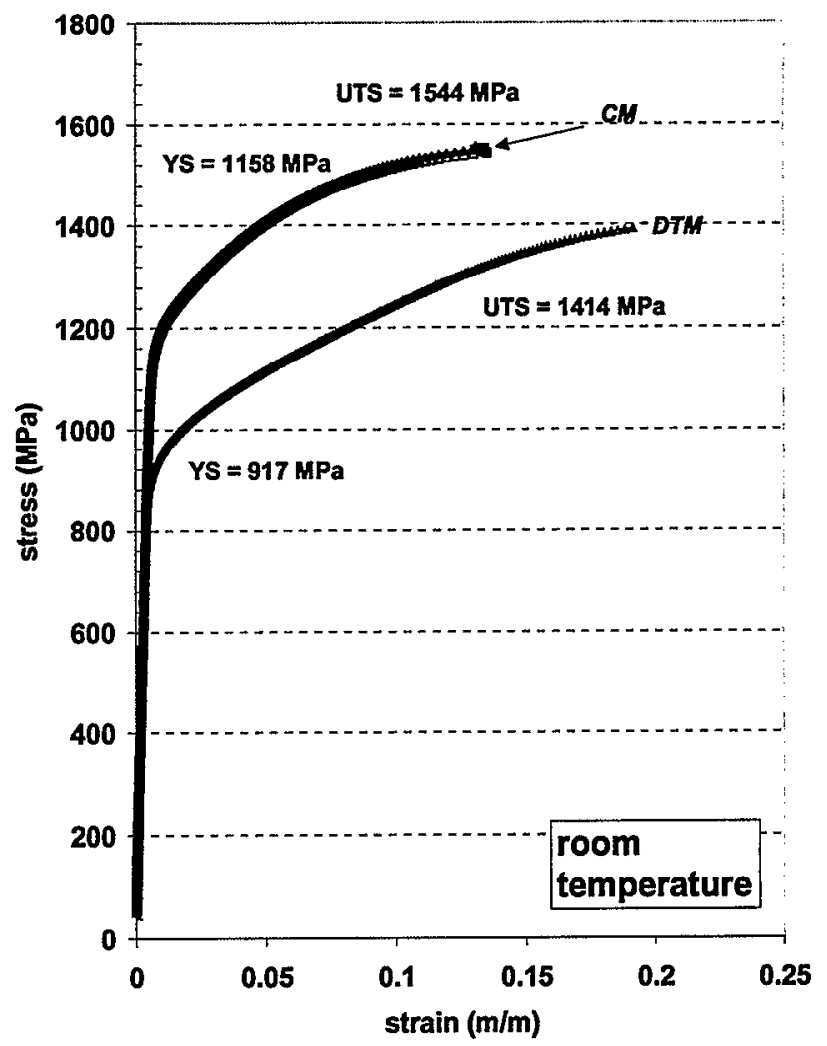

Figure 17: Room temperature tensile test results.

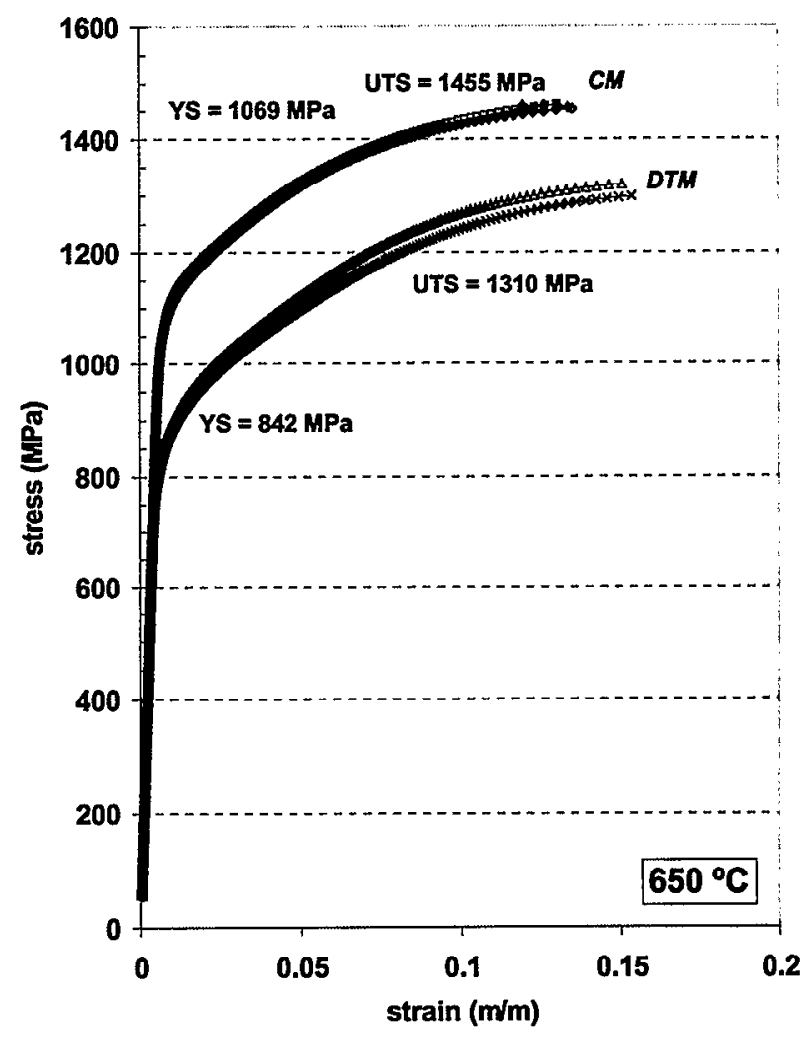

Figure 18: Elevated temperature tensile test results. 
It was also proven that successful characterization of short crack properties is possible utilizing the ACPD crack monitoring technique. This is a significant result for future reference if damage tolerant lifing philosophies are to be implemented in turbine disc design.

\section{Acknowledgements}

This work was conducted at the Institute for Aerospace Research under IAR-NRC project \#46-6JL-04. Financial assistance was also provided by Pratt and Whitney Canada and Carleton University.

\section{$\underline{\text { References }}$}

1. MIL-STD-1783 (USAF): Military Standard, "Engine Structural Integrity Program (ENSIP)", by the Department of Defence, USA, Nov. 1984.

2. MIL-STD-1843 (USAF): Military Standard, "Reliability Centered Maintenance for Aircraft, Engine and Equipment", by the Department of Defence, USA, Feb. 1985.

3. Koul, A.K., Au, P., Bellinger, N., Thamburaj, R., Wallace, W., and Immarigeon, J-P., "Development of a Damage Tolerant Microstructure for Inconel 718 Turbine Disc Material", Superalloys 1988, (The Metallurgical Society, 1988), pp. 3-12.

4. Krueger, D.D., Kissinger, R.D., and Menzies, R.G., "Development and Introduction of a Damage Tolerant High Temperature Nickel-Base Disk Alloy, Rene 88DT", Superalloys 1992, (The Metallurgical Society, 1992), pp. 277-286.

5. Wanhill, R.J.H., "Short Cracks in Aerospace Structures", The Behavior of Short Fatigue Cracks, (Ed. by K.J. Miller and E.R. de los Rios, Mechanical Engineering Publications, London, 1986), pp. 27-36.

6. Evans, W.J., Smith, M.E.F., and Williams, C.H.H., "Disc Fatigue Life Predictions for Gas Turbines", AGARD-CP-368, 1984, paper 11.

7. Koul, A.K., Immarigeon, J.P., Wallace, W., 'Microstructural Control in Ni-based Superalloys", Advances in High Temperature Structural Materials and Protective Coatings, (Ed. by A.K. Koul et al., National Research Council of Canada, Ottawa, Canada), Chapter 6.

8. Mom, A.J.A., Raizenne, M.D., "AGARD Cooperative Test Programme on Titanium Alloy Engine Disc Material", AGARDCP-393, 1985, p.9.

9. Swain, M.H., "Monitoring Small-Crack Growth by the Replication Method", Small Crack Test Methods, Ed. by J.Larsen and J. Allison, ASTM STP 1149, 1992, pp.34-56.

10. Koul, A.K., and Thamburaj, R., "Serrated Grain Boundary Formation Potential of Ni-based Superalloys and its Implications", Metallurgical Transactions A, Vol. 16A, 1985, pp.17-26.
11. Wu, X.J., and Koul, A.K., "Grain Boundary Sliding at Serrated Grain Boundaries", Advanced Performance Materials, (Kluwer Academic Publishers, 1997), Vol.4, 1997, pp.409-420.

12. Wu, X.J., and Koul, A.K., "Grain Boundary Sliding in the Presence of Grain Boundary Precipitates During Transient Creep", Metallurgical Transactions A, Vol. 26A, 1995, pp.905-914.

13. Koul, A.K., and Gessinger, G.H On the Mechanism of Serrated Grain Boundary Formation in Nickel-Based Superalloys", Acta Metallurgica., Vol. 31, No. 7, July 1983, pp. 1061-1069.

14. Reed, P.A.S., and King, J.E., "Comparison of Long and Short Crack Growth in Polycrystalline and Single Crystal Forms of Udimet 720", Short Fatigue Cracks, (ESIS 13, Ed. by K.J. Miller and E.R. de los Rios, London, 1992), pp. 153-168.

15. Newman, J.C. Jr., "Fracture Mechanics Parameters for Small Fatigue Cracks", Small Crack Test Methods, (Ed. by J.Larsen and J. Allison, ASTM STP 1149, 1992), pp. 6-33.

16. Bolingbroke, R.K., and King, J.E., "A Comparison of Long and Short Fatigue Crack Growth in High Strength Aluminum Alloy", The Behavior of Short Fatigue Cracks, (Ed. by K.J. Miller and E.R. de los Rios, Mechanical Engineering Publications, EGF.1, 1986), pp.101-114.

17. Radhakrishnan, V.M., and Mutoh, Y., "On Fatigue Crack Growth in Stage I", The Behavior of Short Fatigue Cracks, (Ed. by K.J. Miller and E.R. de los Rios, Mechanical Engineering Publications, EGF.1, 1986), pp.87-99.

18. Blom, A., et al., "Short Fatigue Crack Growth Behavior in $\mathrm{Al}$ 2024 and Al 7475", The Behavior of Short Fatigue Cracks, (Ed. by K.J. Miller and E.R. de los Rios, Mechanical Engineering Publications, EGF.1, 1986), pp.37-66.

19. Bain, K.R. et al., "Development of Damage Tolerant Microstructures in Udimet 720", Superalloys 1988, (The Metallurgical Society, 1988), pp. 13-22. 